\title{
Extending Theoretical Understanding for Defining the Capabilities of Big Data Analytics in Organisations: a Thematic Analysis
}

\section{Renu Sabharwal}

Newcastle University Business School

Shah Jahan Miah ( $\square$ shah.miah@newcastle.edu.au )

The University of Newcastle Business School https://orcid.org/0000-0002-3783-8769

\section{Survey paper}

Keywords: Big Data, Organization, Systematic literature review, Big Data Analytics capabilities

Posted Date: July 9th, 2021

DOl: https://doi.org/10.21203/rs.3.rs-694446/v1

License: (c) (1) This work is licensed under a Creative Commons Attribution 4.0 International License.

Read Full License 


\section{Abstract}

Big Data Analytics (BDA) have been proliferated to academic researchers and industry practitioners over the past few years. As a prominent data-driven decision application, the BDA capabilities in organisation have been recognised, but limited studies have successfully attempted to communicate an authentic understanding on BDA capabilities that may enhance the current theoretical knowledge. While big data have been defined in various ways with its characteristics of shared definitions, it is important to explore the classification of BDA and its capabilities considering its advantageous opportunities. This study conducts a review study adopting the well-known PRISMA methodology, integrating a thematic analysis approach using NVIV012. The study analyses 70 elected sample articles for generating new insights of BDA, informing through organisation development theory and leading to this an empirical research model is outlined for further validity assessment. It is anticipated that the findings would be contributing to address dynamic clarity and relevance of adopting BDA application.

\section{Introduction}

Organisations in this modern era involve in data harvesting [e.g. data collections] continuously from their users for improving relevance and practices. Huge volume of stored data or data of electronic transactions have become a central element of supporting their decision making. Practitioners such as managers, policymakers and executive officers embrace different latest technological solutions to covert the huge datasets into new insights to make their regular or strategic decision making. While the data analysis involves multiple facets and approaches, an innovative data-handling method is recognized as "Big Data Analytics" (BDA) that has been proliferated in recent years to practitioners. BDA mainly encompasses computational intelligence techniques that are used to remedying data to convert them into decision-support information.

Decision making in organisations are being increasingly entangled to use of big data for evidence-based decision making, which makes the applications of various analytics an obvious practice (Mikalef, Boura, Lekakos \& Krogstie, 2019). Towards improving robust BDA research for offering practical value-adding in organisations become more essential than ever (Kolajo, Daramola and Adebiyi, 2019). It is therefore, a paramount task to conduct "systematic review of big data streams analysis which employed a rigorous and methodical approach to look at the trends of big data stream tools and technologies as well as methods and techniques employed in analysing big data streams" (Kolajo et al. 2019, p.1). Although this implies towards technical evolvement of BDA, insights of BDA capabilities are considered as significant piece of knowledge for researchers (Jha et al. 2020). It is important to unification of BDA to support organisational decision-making through developing suitable theoretical understanding or extending existing theories remains a significant challenge. Better BDA that meets organisational requirements may ensure better products as well as service improvements for consumers' optimised outcome.

Previous systematic literature reviews have been focused on aspects, such as BDA adoption challenges in future (Posavec and Krajnovic, 2016; Madhlangobe and Wang, 2018; Saetang, Tangwannawit \& 
Jensuttiwetchakul, 2020) while some studies focused technical innovation aspects of big data analytics only (Pei, 2020; Marashi and Hamidi 2018). This implies that numerous studies have examined big data issues in different domains. These initiatives include: quality of big data in financial service organisation (Haryadi et al., 2016); organizational value creation due to BDA usage (George \& Chandra, 2021); application of big data in health organisation (Marashi \& Hamidi, 2018); decision improvement using big data in health (Sousa et al., 2019); application of big data in transport organization (Du, Zhang \& Ni, 2019); relationship between big data in financial domain (Wahyudi, Farhani \& Janssen, 2018); issues of big data in government organisations (Alkatheeri et al., 2020).

While there may be a growing circulation of literature on BDA, limited attention has been experienced to explore the capabilities of BDA and how the organisations may obtain advantages from those capabilities (Gupta \& George, 2016). The objective of this study to fill such a gap of literature review, adopting PRISMA framework guidelines to produce important insights using qualitative thematic analysis. Main determination of the study is to present an overview of findings as well as their implications for further empirical research development. Therefore the central aspects are to (1) provide insights of key themes of BDA capabilities about the BDA state of the art in research, (2) show an alignment to other established contributing theories in terms of a new empirical research model for further quantitative research for the scientific communities of BDA capabilities in organisations.

The rest of the paper is structured as follows. In Sect. 2, we describe the study background which is included - the gap in previous literature of BDA and potential application of BDA. Next in Sect. 3, we describe the research methodology used to conduct the systematic literature review which outline the PRISMA process and associative meta-analysis. The next Sect. 4, we summarise the findings which include the process of defining the BD, BDA and BDA capabilities (BDAC) in the organisation. In Sect. 5, we outline the overall discussion following Sect. 6 for summarising our research on BDAC in the organisation.

\section{Study Background}

BDA has been diversified in different forms for meeting organisation specific decision support demands. Tiwari et al. (2018) describe different classes of BDA: 1) descriptive analytics that deals with straightforward question of what is or has happened and why. It deals with "opportunities and problems" utilising descriptive statistics such as historical insights. 2) predictive analytics that deals with a bit complicated questions such as what will be happening or likely to be happened, by exploring data patterns utilising relatively complex statistics, simulation and machine learning algorithms. For example, it is used for identifying trends of sales activities, forecasting customer behaviour and their purchasing patterns. 3) prescriptive analytics that deals with the complex question of what should be happening and how to influence it, utilising complicated forms of descriptive, predictive analytics with mathematical optimization, simulation, and machine learning algorithms. For instance, many large-scale companies have adopted prescriptive analytics to optimize their productions or solving scheduling and inventory 
management issues. Regardless of different types, the application of BDA has of paramount impact both in terms of tangible and intangible resources in organisations.

\subsection{Gap in previous relevant studies of BDA}

We classify previous studies of BDA into two main broader groups within non-technical context of studies. First group relates to develop new BDA requirements and functionalities in a specific problem domain while the second is to focus on more intrinsic aspects such as capabilities development or valueadding due to impact in particular business aspects. Following Table 1 includes some examples of existing review studies that are mainly highlighted on technical or problem-solving aspects.

Table 1

Existing literature review studies of BDA

\begin{tabular}{|c|c|c|}
\hline Sources & Review methods & Key findings \\
\hline $\begin{array}{l}\text { Kolajo, } \\
\text { Daramola \& } \\
\text { Adebiyi } \\
(2019)\end{array}$ & $\begin{array}{l}47 \text { articles, content } \\
\text { analysis for } \\
\text { discovering issues }\end{array}$ & $\begin{array}{l}\text { Importance of designing streaming analytics for big data } \\
\text { found scalability, privacy and load balancing issues of big } \\
\text { data technologies. }\end{array}$ \\
\hline $\begin{array}{l}\text { Mikalef, } \\
\text { Pappas, } \\
\text { Krogstie \& } \\
\text { Giannakos, } \\
(2018)\end{array}$ & $\begin{array}{l}84 \text { articles, } \\
\text { systematic literature } \\
\text { review method }\end{array}$ & $\begin{array}{l}\text { Explain existing mechanisms of BDA leading to } \\
\text { competitive performance gains for building theory aligning } \\
\text { to the resource-based and dynamic capabilities. }\end{array}$ \\
\hline $\begin{array}{l}\text { Nguyen et al. } \\
(2018)\end{array}$ & $\begin{array}{l}413 \text { articles, content } \\
\text { analysis }\end{array}$ & $\begin{array}{l}\text { Develop classification framework identifying supply chain } \\
\text { functions with BDA models. }\end{array}$ \\
\hline $\begin{array}{l}\text { Günther et al. } \\
\text { (2017) }\end{array}$ & $\begin{array}{l}67 \text { articles, } \\
\text { Systematic review }\end{array}$ & $\begin{array}{l}\text { Examine how organisation may realise values of big data, } \\
\text { analysing two socio-technical features: portability and } \\
\text { interconnectivity influence. }\end{array}$ \\
\hline $\begin{array}{l}\text { Rialti et al. } \\
(2019)\end{array}$ & $\begin{array}{l}170 \text { articles, } \\
\text { bibliometric analysis } \\
\text { and systematic } \\
\text { literature review. }\end{array}$ & $\begin{array}{l}\text { Create } 4 \text { clusters and examine that BDAC and } \\
\text { organisational objectives are aligned so organisations } \\
\text { should develop new strategies for dynamic capabilities of } \\
\text { BDA. }\end{array}$ \\
\hline $\begin{array}{l}\text { Wamba \& } \\
\text { Mishra (2017) }\end{array}$ & $\begin{array}{l}49 \text { research papers, } \\
\text { bibliometric and } \\
\text { network analysis } \\
\text { review }\end{array}$ & $\begin{array}{l}\text { Identify clusters of big data for improving business } \\
\text { processes in organisation. }\end{array}$ \\
\hline $\begin{array}{l}\text { Wang \& Hajli } \\
(2017)\end{array}$ & $\begin{array}{l}109 \text { articles, } \\
\text { Descriptive review }\end{array}$ & $\begin{array}{l}\text { Reveal on how to establish BDAC for business } \\
\text { transformation. }\end{array}$ \\
\hline $\begin{array}{l}\text { Kolajo, } \\
\text { Daramola \& } \\
\text { Adebiyi } \\
\text { (2019) }\end{array}$ & $\begin{array}{l}47 \text { research articles, } \\
\text { theoretical review }\end{array}$ & $\begin{array}{l}\text { Explain big data streams and find gap about pre- } \\
\text { processing stage of big data streams and develop } \\
\text { scalable framework to accommodate data stream } \\
\text { computing mode. }\end{array}$ \\
\hline $\begin{array}{l}\text { Tiwari et al. } \\
(2016)\end{array}$ & $\begin{array}{l}100 \text { sample articles, } \\
\text { content analysis }\end{array}$ & $\begin{array}{l}\text { Address big data issues, trends and views in SCM to } \\
\text { spread big data value-adding perspective. }\end{array}$ \\
\hline
\end{tabular}


Second group of literature is associated to examine BDA in organisational context, such as for capabilities at some extent in specific business domains (Akter et al., 2016). Existing studies leverage BDA leading to different aspects of organisational performance (Kwon et al., 2014, Chen et al., 2015; Kim \& park, 2017; Wamba et al., 2017; Wang \& Hajli, 2017; Mikalef et al., 2018). Research also have extended on prime aspects of BDA, which are to improve data utilisation and decision support qualities. For example, Popovič et al. (2016) explained how BDAC may be developed for leading better managerial decision-making process. Jha et al. (2020) conducted thematic analysis over 15 firms for exploring new phenomena by theorizing new constructs. These types of studies have been limited to identify the factors related to the success of BDA capability, in particular domain such as supply chain. Table 2 summarises existing relevant studies that leverage BDA. 
Table 2

Some examples of BDA capabilities studies

\section{Sources Method Findings}

Kwon et Quantitative analysis al. $\quad 306$ online surveys (2014) Jha et $\quad 14$ firms, thematic analysis al. (2020).

Chen et Quantitative analysis al. (2015)

Akter et Quantitative - 152 online al. (2016)

Gupta \& George (2016)

$$
\text { surveys }
$$

Quantitative analysis 108 online surveys from 108

executive-level technology leaders

$\begin{array}{ll}\text { Popovič } & \text { Qualitative- } 3 \text { exploratory } \\ \text { et al. } & \text { case study }\end{array}$

Firm's intention for BDA and its competence for maintaining the quality of corporate data and decision making

Identifying the factors inhibiting BDA capabilities in organisations and maximizing its gains throughout BDA applications

Impacts and antecedents of organisational BDA utilization
Effect of BDAC on organisational performance and moderating the impact on the relationships of capabilities and performance.

BDA capability leading to organisational performance

\section{Examined how the usage of BDA}

Enhances operations and displayed its link with operations performance

Explored that the data and organization have greater impacts than technology and support domains

$\begin{array}{lll}\text { Kim \& } & \text { Quantitative- Online } 30 & \text { Explored that the data and organization have greater } \\ \text { Park } & \text { survey } & \text { impacts than technology and support domains } \\ \text { (2017) } & \end{array}$

Wamba Quantitative - 297 online et al. surveys from Chinese IT (2017) managers (2017)

Mikalef Quantitative- 202 et al. technology leader in (2018)

$\begin{array}{lll}\text { Wang \& } & \text { Quantitative- } 109 \text { case } & \begin{array}{l}\text { Reveals that how to establish BDAC for business } \\ \text { Hajli }\end{array} \\ \text { description analysis } & \text { transformation. }\end{array}$

technology leader

Confirmed that BDAC has both direct and indirect impacts on FPER.

Reveals that how to establish BDAC for business

Explained that BDAC can be advantageous to enable and support organizational capabilities.

\subsection{Potential applications of BDA}

Analysis of BDA offers potential benefits in organisations. There are many retail organisations in which various analytical approaches are in operation to bring advantage and gain organisational success (Hewage, Halgamuge, Syed \& Ekici, 2018). Therefore, modern organisations increasingly invest in BDA projects for cost-cutting, benefits realisations, and futurist business planning. For example, Amazon became the first in the line, as an online retailer, maintaining its position for innovative BDA improvement 
and use (Hewage, Halgamuge, Syed \& Ekici, 2018). The following paragraphs presents some successful stories of using BDA in the relevant sector.

- Retail: business organisations utilise BDA for its advantage in the purpose of dynamic pricing (BenMark, Klapdor, Kullmann \& Sundararajan, 2017). Dynamic pricing implies surge pricing and it is used in a way to adjust the price of a product or a service based on its demand and supply. For instance, Amazon uses dynamic pricing keeping the pricing on track of the demand of the products.

- Hospitality. Organisation gains significant values from the use of BDA, for example in improving sales in the Marriott hotels (Richard, 2017). Marriott is known as largest hospitality agent that holds $s$ rapidly increasing number of hotels and serviced customers.

- Entertainment. BDA use in Netflix has created remarks of success (Fouladirad, et al. 2018). The current retention rate stands at around $93 \%$ and it is the ingest in the industry. However, it is not just the retention rate that makes Netflix a success, it is the way the company uses the user data to increase sales as well as profits (Hadida, Lampel, Walls \& Joshi, 2020).

- Transportation: Uber, a well-known company, uses BDA (Harinen \& Li, 2019) for capturing big data of various consumers along with the best routes to locations. Uber eats despite competing with others deliver food in the shortest possible time.

- Food service: McDonald as the fast food restaurant maintains updated information through the use of BDA, right after their recent shifting to healthy food practices, selling food that was good for the health of the consumers (Anaf, Baum, Fisher, Harris \& Friel, 2017), adopting dynamic menu (Wired, 2019).

- Finance: The credit card and payments giant has been using BDA to its advantage for a long time. It is one of the first companies that understood the absolute advantage of using BDA to boost the performance of business (Bernard, 2018). This company collects big data from the ways in which consumers make purchases online and offline and then predict how they are going to shop in the coming time.

- Manufacturing: General Electric, as a manufacturer and distributor, include wind turbines, locomotives, aeroplane engines, and ship engines (Zhang, Huang \& Bompard, 2018). This company had no way of knowing or predicting when an engine or a part was going to fail or may need repairs.

- Online business: Music streaming websites have become a big hit in recent times and they are growing in size and scope mainly because more and more consumers want a customised streaming service (HBS, 2020). For example, there are a large number of streaming services like Apple Music, Spotify, Google Music and more are in use of various BDA applications such as for suggesting new songs to the consumers.

\subsection{Organization value assessment with BDA}

It is vital to establish the specific performance measure that relies on the number of contextual factors along with the area in which BDA deployed. Mneney \& Van Belle (2016), explained that organisations are 
would be ready for adopting BDA, if organisations structure is supportive to enable the realisation of BDA benefits.

\subsubsection{Organisational development and BDA}

Organisation requires effective process for executing operations such as: continuous diagnosis, action planning, and implementation \& evaluation of BDA leading to assist decision making for organisational growth. In earlier literature, Organisational Development (OD) theory, which was created by Kurt Lewin in 1940 , defines processes with the goal of transferring knowledge and skills to organizations. The process mainly is to improve the capacity for solving problems and managing future change. Beckhard (1972) defined that organisation development explains internal dynamics of organisation and "involves when a collection of individuals attempts to function as a group" having goals of improving organisational effectiveness, including organisational capabilities and work performance as well as its ability to adjust culture, policies, practices, and procedure requirements.

Organization development is "a system-wide application and transfer of behavioural science knowledge to the planned development, improvement, and reinforcement of the strategies, structures, and processes that lead to organization effectiveness" (Cummings \& Worley, 2009, p.2). It has three concepts: Organisational climate, organisational culture and organisational capability (Glanz et al., 2008). Organisational climate- is defined "as the mood or unique personality of an organisation" (Glanz et al., 2008, p.343) which included the shared perceptions of policies, practices, and procedures. The climate features also consist of leadership, communication, participative management, and role clarity.

Organisational culture involves the shared basic assumptions, values, norms, behavioural patterns, and artefacts. Schein (1985) defined the organisational culture "as a pattern of shared basic assumptions that was learned by a group as it solved its problems of external adaptation and internal integration" (p.38). The organisational capacity implies the function of the organisation, such as production of services or products, or maintenance of organisational operations. A framework was developed by Prestby \& Wandersman (1985), which explained four components of organisational capacity - resources acquisition, organisation structure, production subsystem and accomplishment. Organisational culture

and climate effect any organisation's capacity to operate adequately. Figure 1 illustrates the relationships among this component in the framework.

\section{Research Methodology}

This research is mainly classified as a systematic literature review, which represents a research process of analysing and examining the relevant research as well as for gathering and evaluating the existing research (Liberati et al.,2009). This systematic review is conducted in accordance with the PRISMA framework (Page et al., 2021). PRISMA provides reporting guidance that reflects advances in methods to identify, select, appraise, and synthesise existing studies. Keywords were searched to find out published articles related to the application of BDA. Our review represents through the framework as a guide of the 
process that includes identify the review samples, select \& appraise the review samples and then synthesis the outcome (Page et al., 2020).

In this research, we adopted five stages of the process of literature review as follows:

Stage1: Design Development

In this stage, the main question is established that instructed the selection and search strategy, analysis and synthesis process to define the aim, scope and specific research goals in accordance with the guidelines, procedures and policies of the Cochrane Handbook for Systematic Reviews of Intervention (Higgins and Green 2008). The design review process was directed by the following research question: What are the consensual definitions of BDA, unique attributes, objections and business revolution with BDA?

Stage2: Inclusion and elimination criteria

In order to maintain the nuances of the systematic review, a number of inclusion and exclusion precedents were applied. The inclusion criteria only focused on the topics around" Big Data in Organization". The publication year was selected between 2015 to 2021 and accept only English language journal articles. The English language articles were selected and essential keywords were only used to find the most relevant articles "Big Data in Organization" and Truncation, wildcarding and appropriate Boolean operators were used. Only three databases were used to find the relevant literatureScience Direct, Web of Science, IEEE and Springer Link.

Table 3

Outcome of stage 1 (number of papers)

\begin{tabular}{|lllll|}
\hline Science Direct & Web of Science & IEEE & Springer Link & Total \\
\hline 155518 & 8834 & 3235 & 63000 & 230587 \\
\hline
\end{tabular}

Table 4

Outcome of stage 2 (number of papers)

\begin{tabular}{|lllll|}
\hline Science Direct & Web of Science & IEEE & Springer Link & Total \\
\hline 107067 & 7111 & 2471 & 30000 & 146649 \\
\hline
\end{tabular}

Table 5

Outcome of stage 3 (number of papers)

\begin{tabular}{|lllll|}
\hline Science Direct & Web of Science & IEEE & Springer Link & Total \\
\hline 7735 & 46 & 22 & 259 & 8062 \\
\hline
\end{tabular}


Table 6

Outcome of stage 4 (number of papers)

\begin{tabular}{|lllll|}
\hline Science Direct & Web of Science & IEEE & Springer Link & Total \\
\hline 63 & 43 & 20 & 35 & 161 \\
\hline
\end{tabular}

Table 7

Outcome of stage 5 (number of papers)

\begin{tabular}{|lllll|}
\hline Science Direct & Web of Science & IEEE & Springer Link & Total \\
\hline 34 & 10 & 17 & 9 & 70 \\
\hline
\end{tabular}

Stage 3: Literature sources and search approach

In stage 3, the research articles are excluded on basis of Topic, Keywords and Abstract. At this stage, the number of retained articles after the above-mentioned process was 8062 .

Stage 4: Quality examination

At this stage, for each of the 161 research articles that remained after stage 3 , only the title: Big Data in Organization" was used.

Stage 5: Literature extraction and synthesis process

At this stage, only journal articles, conference papers and books articles were selected and exclude those articles whose full texts are not electronically available. At this stage, 56 articles were excluded and only 70 papers were selected.

\subsection{Meta-Analysis of the selected paper}

We have found 70 papers that met the section criteria. After the analysis process, the publication year and type were presented in Table 6 which indicates the increasing trends in big data analytics over the 6 years period. Another fact has been found that the Journals produced more BDA papers than Conferences.

The below pie chart presents the research articles published in their respective years which is presenting $6 \%$ of articles has been published in the year $2015,13 \%$ in $2016,14 \%$ in $2017,16 \%$ in the year $2018,20 \%$ in the year 2019, 21\% in the year 2020 and $10 \%$ in the year 2021 .

\section{Findings}

According to Mikalef et al., (2018), the first step of the systematic literature review is to describe the key approach and establish the definitions of each key concept. A six-phase analysis process is used for identifying, analysing, and reporting themes in a step-by-step manner using NVIVO 12. Braun and Clarke 
(2006) described, thematic analysis is a method used for "identifying, analysing, and reporting patterns (themes) within the data" (p.79) and also defined, "rigorous thematic approach can produce an insightful analysis that answers particular research questions" (p.97). The combination of Nvivo and Thematic analysis presents the better results. Judger (2016) defined, "using both the computer assisted data analysis coupled with manual checks, it improves trustworthiness, credibility and validity of findings" (p.6). We adopt this practice manually with the thematic analysis to develop four separate units of analysis such as - Big data, BDA, BDA capability and BDA themes. The five BDA themes are classified based on a time-consuming manual process due to ensuring accuracy with appropriate judgemental perception. After establishing key definitions and key concepts among samples were cross-checked.

\subsection{Defining Big Data}

Out of 70 samples, a total of 33 papers provides a clear replicable definition of big data, but only most popular definitions have been presented in the below Table 8 [only most popular five definitions are included]. Most of the definitions provide key elements that are indispensable to define big data as conceptual components.

Table 8

Big Data Definitions

Author Definition
details and
year

Khine and "A large volume of digital data found in government organizations which require Shun different speed i.e. velocity based on the requirements of the government application (2017) domains with a wide variety of data types and sources, and these government big data must be able to guarantee veracity to extract desired value for the target government organization" (p.41).

Zan (2019) "Big data in information technology is a set of approaches, tools and methods for processing structured and unstructured data of huge volumes and considerable diversity for obtaining human-perceptible results" (p.1).

Ekambaram "Big data is about a large amount of data that require a new way to process them. et al. (2018) Traditional databases cannot adequately address issues related to collect, store, process or analyze the huge data sets"(p.853).

Rialti et al. "Big data are data sets so complex that cannot be managed or analyzed using (2018) traditional data analysis software. These data sets share 7 common characteristics, the 7Vs: V1-Volume, V2-Velocity, V3-Variety, V4-Veracity, V5-Value, V6-Variability \& V7-Visualization" (p.1094).

Wang et al. "Big data was first defined in terms of its volume, velocity and variety (3Vs). Then a (2019) fourth $V$ was added, 'veracity', which refers to data accuracy that relates to quality. After which it became possible to develop more sophisticated data analysis software to fulfil the needs of handling the information explosion according to the way it is accessed, searched, processed and managed"(p.364).

\subsection{Defining BDA}


Out of 70 sample articles, a total of 21 articles give a clear definition of BDA but only most being used definitions has been selected in the below Table. Some scholars define BDA to accentuate the tools and the process used to derive new insights from big data. Following Table 9 shows some examples.

Table 9

BDA definitions

\section{Author Definition \\ Details}

De $\quad$ "Big data analytics defined in six components - data generation, data acquisition, data

Mauro storage, advanced data analytics, data visualization, and decision-making for value-

et al. creation), its typical tools, techniques and technologies, and its main domains of

(2018) application"(p.755).

Rialti et "Big data analytics presented as the next revolution which allows the management to al. measure radically more about their business and to directly translate that knowledge into (2018) decision making and performance" (p.1095).

Sousa "Big data analytics enables large-scale data sets integration, supporting people et al. management decisions, and cost-effectiveness evaluation of healthcare organizations" (2019) (p.1).

Batistič "Big data analytics is defined as a process to analyze the large data volumes to capture and Laken (2019)

\subsection{BDA and its definitions of capability}

Only $16 \%$ of the articles are focused on the big data characteristics while some presented the challenges and issues during the adoption and implementation process of acquiring big data in organizations (Mneney and Van Belle 2016). Our findings suggest that BDA capability to use the large volumes of data generated through different devices and people to increase efficiency and generate more profits. Mneney and Van Belle (2016) explained the BDA capability in same way. BDA capability and its potential value could be more than the businesses expect (Jokonya 2015). Some research suggested that professional services, manufacturing and retail have relatively lower degrees of barriers to overcome than other business sectors. We like to define the BDAC as a combined ability to store, process and analyses a big amount of data for delivering meaningful information to the users. A previous study outlined four dimensions of BDA capability: data integration capability, analytical capability, predictive capability, and data interpretation capability. 
Big Data analytics capability definitions

\begin{tabular}{|c|c|}
\hline $\begin{array}{l}\text { Author } \\
\text { Details }\end{array}$ & Definition \\
\hline $\begin{array}{l}\text { Mikalef } \\
\text { et al. } \\
\text { (2020) }\end{array}$ & $\begin{array}{l}\text { "BDA capability is defined as the ability of the organisation to collect and analyse the } \\
\text { data toward the generation of insights, by effectively developing its data, technology and } \\
\text { talent through organisation-wide processes, roles and structures" (p.2). }\end{array}$ \\
\hline $\begin{array}{l}\text { Wang et } \\
\text { al. } \\
(2019)\end{array}$ & $\begin{array}{l}\text { "Big data capability is presented as the ability to acquire, store, process and analyse a } \\
\text { large amount of data" (p.13). }\end{array}$ \\
\hline $\begin{array}{l}\text { Shuradze } \\
\text { and } \\
\text { Wagner } \\
(2016)\end{array}$ & $\begin{array}{l}\text { "BDA capability as the organisation's ability to mobilize and deploy data analytics related } \\
\text { resources in combination with marketing resources and capabilities" (p.3). }\end{array}$ \\
\hline $\begin{array}{l}\text { Gupta } \\
\text { and } \\
\text { George } \\
(2016)\end{array}$ & $\begin{array}{l}\text { "Big data capability is defined as firms need a combination of certain tangible, human } \\
\text { and intangible resources to build BDA capability" (p.1050). }\end{array}$ \\
\hline
\end{tabular}

\subsection{BDA themes}

It is viable to identify outstanding issues of research that are of excessive relevance which has termed in five themes using NVIV012, presented in Fig. 5. Following Table 10 illustrates them in detail and provide some suggestion by creating the research framework model on how the future researchers could approach these problems. 


\section{Research \\ Category - \\ Themes}
Resource concinnity of
Big data analytics
Only $12 \%$ have focused to define about implementing BDAC, but very limited knowledge has been provided in orchestrating and handling such resources to build $B D A C$ in organization. It is essential to growing the potential so that can leverage these resources strategically. Therefore, it is decisive for future research to examine the proficient-building process.

Big Data proficiencies

Only $7 \%$ focused on the organisation's proficiency and very less knowledge provided on Big data proficiency, it is vital to differentiate between those two. Fundamentally, an organization can implement and develop substantial BDA proficiencies, but the utilization is only towards specific organisation functions such as finance, marketing etc. Therefore, the future research should focus on BDAC efficiency as well as organization's proficiency.
Big Data into actionable insight
To comprehend the value of BDAC, it is vital to turn the data into actionable insights to reach better and optimized organization decisions and only $15 \%$ research articles focused on turning BDAC into action. Hence, the organization may depend upon many important factors which can be experimented in future research using framework of BDAC and OD.

Management attitude towards Big Data and its impact

Only $18 \%$ studies have confirmed that the organisation's management normally decides to implement Big data, but does not fully support the capability on the decision-making process and the management use prediction technique over BDA result which has been studied and found in only $12 \%$ articles presented Management. The investment in BDA capabilities is affected by the disagreement of top management and very limited knowledge about BDA capabilities.

Organization value assessment with $B D A$
It is vital to establish the specific performance measure that relies on the number of contextual factors along with the area in which BDA deployed. Only $7 \%$ past selected articles viewed that Orgaisations are ready for BDA implementation but Organisations structure needs to be supportive to enable the realisation of more benefits of BDA.

Manyika et al. (2011) explained that big data analytics would help an organisation to improve decision making, minimise the risks and other valuable insight that would otherwise remain hidden. The authors also explained that using big data analytics could help in creating new innovative business model and can improve organisation's performance.

The above analysed themes-1) Resource concinnity of Big data analytics, 2) Big Data proficiencies, 3) Big Data into actionable insight, 4) Management attitude towards Big Data and its impact and 5) Organization value assessment with BDA presented the problems from the past literature which will be examining in the proposed research framework using four hypotheses.

The below theoretical model presents that organisational level as well as individual level is influenced by organisation climate, culture and capacity which can help to understand how BDA should be utilised to improve organisational performance as well as individuals. 


\subsection{Our interpretation through developing a new research model}

This study interprets the findings of the literature review through a new research method development. One of the vital connections of BDA capability to resource based views was the main driving force here. BDA tools classified into three resources- tangible (financial and physical resource), human skills (employees' knowledge and skills) and intangible (organisational culture and organisational learning) which has been used in the IS capacity literature (Grant 2010; Bharadwaj, 2000; Chae et al., 2014 and Santhanam \& Hartono, 2003). Gupta \& George (2016) explained how seven factors of three resources allow firms to create BDA capability.

To develop the robust model, the above three types of resources should be implemented in the organisation and make a contribution to the emergence of high order approach. This research model presents that BDAC enhances organisational development which strengthens the organisational strategies and the relationship between $\mathrm{BD}$ resources and $\mathrm{OD}$. The below figure is a theoretical framework that illustrated how BDA resources influence the sustainability of innovation and organisational development (Hao, Zhang \& Song, 2019)

Miller (2014) defined that data has become a strategic business asset and recommended for future research that Business and academia must participate to gain more knowledge about BD skills and capability across the organisation. The study concluded that every profession, whether business or technology will be impacted by big data and analytics. Gobble (2013), explored that the organisation should invent new technologies which provide necessary supplements to enhance the firm's growth. Ann Keller et al. (2012), described that Big data is bringing a revolution in science and technology and recommended to take Big data challenge with the expectation of making a data-rich smart city. Galbraith (2014) explored how an organisation attempt to develop a BDAC, can encounter obstacles as well as opportunities. The past literature does not provide any observational publication that has bound Big data analytics capability and Organisational Development or adorned their interaction. There is very little empirical evidence on the agreement of OD and BDA or their characteristics and feature. So this research would be filling that gap by creating the below research model.

This proposed research model presents the direct connection between the BDAC and OD which has a direct effect on OD three concepts - Organisational Capacity, Organisational Culture, Organisational Climate, and their further resources. The research has proposed the following hypothesis which can be researched in future.

BDAC can help in any organisational development with implementing new technology tools. Extensive support for this relation can be found in related empirical studies on the effect of BDAC for improvement of organisation's performance or development (Akter et al., 2016; Alkatheeri et al., 2020; Wang et al., 2016). From the preceding discussion, it is hypothesized that: 
H1: There is a positive relationship between Organisational Development and BDAC.

The organisational capacity heavily relies on organisational development or in other words, organisational capacity (OC) is a resource of any organisation which requires development. Accordingly, with support of past studies on relationship between Organisational capacity and Organisational Development (Cummings \& Worley, 2009; Glanz et al., 2008). Organisational development can improve Organisational capacity. Thus, it is hypothesized that:

H2: There is positive relationship between Organisational Development and Organisational Capability.

With the implementation or adoption of BDAC, Organisational culture is impacted. The above statement is supported by Schein (1985). Big data enables the organisation to diffuse their inefficient practices whether it is marketing, retails or media organisation. From the above discussion, it is hypothesized that:

H3: There is positive relationship between BDAC and Organisational Culture.

BDAC adoption can affect organisation's Climate which are policies, practices and measure which are associated with an individual experience that is supported by (Schneider et al., 2013). In other words, BDAC can improve the business climate as well as individual's performance.

From the above discussion, it is hypothesized that:

H4: There is positive relationship between BDAC and Organisational Climate.

This research is based on the requirement of developing a new framework in relation to Organisational Development theory because the modern organisation cannot ignore the involvement of BDA and its future learning and association with theoretical understanding. Therefore, this research paper aims to demonstrate current trends of different capabilities and a framework to understand BDAC in a better way for future research.

\section{Overall Discussions}

It is an obvious that big data research is getting huge interests. From the 2015 to 2021, in terms of percentage, the research journal article published in 2020 was the highest published year with $21 \%$. BDAC can improve business-related outcomes which included more effective marketing, new revenue opportunities, customer personalization and improved operational efficiency. But the past literature is focused on only one or two aspects of BDAC even though big data is more capable to enhance organisational growth. We formed a new research model to represent relationship between BDAC and OD for understanding impact on organisational capacity. We argue that this understanding enhances current knowledge of BDAC that may better meet organisational requirements ensuring improved products as well as service improvements for consumers' optimised outcome. 
Many research has been conducted in a different context about Big Data but BDAC in the organisation is still an open issue included how to utilise this solution in order to organisational development. It is very important to leverage the full potential of BDA and how can they offer with the purpose of gaining an advantage. Therefore, this research focus on summarising by creating the themes but still have observational limitation understanding. Then, the research proposes a new research model which followed the prior literature (Mikalef et al., 2020) in the context of business.

In this systematic review, while authors explored Springer Link, IEEE, Science direct, Web of science which index high impact journal and conference papers, there is the possibility that some relevant journals could have been missed. The research has been constrained based upon the selection criteria of the literature included year, English language, and peer-reviewed journal articles and omitted reports, grey journals and web articles.

\section{Conclusion}

As a result of this literature review, five themes have been presented to leverage BDA in an organisation and gain a competitive advantage. To this end, a research model is presented, and four hypotheses have been created which can bridge the gap between BDA and organisational development. The research model reveals the BDA resources- tangible, human skills and intangible and created four hypotheses to bridge the gap between organisational development and BDAC which can be addressed in future research. This research model was developed to advocate the key themes that we gathered from the literature review. It is aimed to provide the empirical insights if determining an impactful change in BDA implementation in organisation.

\section{Abbreviations}

- IEEE-The Institute of Electrical and Electronics Engineers

- BD- Big Data

- BDA-Big Data Analytics

- BDAC- Big Data Analytics Capabilities

- OD- Organisational Development

- OC- Organisational Capacity

\section{Declarations}

- Ethics approval and consent to participate

Not applicable

- Consent for publication 
Not applicable

\section{- Availability of data and materials}

Data will be supplied upon request.

- Competing interests

Not applicable

- Funding

Not applicable

\section{- Authors' contributions}

First author conducted the research while the second author has ensured quality standard and rewritten the entire findings linking to underlying theories.

\section{- Acknowledgements}

Not applicable

\section{References}

1. Akter S, Wamba SF, Gunasekaran A, Dubey R, Childe SJ. How to improve firm performance using big data analytics capability and business strategy alignment? Int J Prod Econ. 2016;182:113-31.

2. Alkatheeri Y, Ameen A, Isaac O, Nusari M, Duraisamy B, Khalifa GS. The effect of big data on the quality of decision-making in Abu Dhabi Government organisations. In: Data management, analytics and innovation. Singapore: Springer; 2020. pp. 231-48.

3. Anaf J, Baum FE, Fisher M, Harris E, Friel S. Assessing the health impact of transnational corporations: a case study on McDonald's Australia. Globalization health. 2017;13(1):7.

4. Ann Keller S, Koonin SE, Shipp S. Big data and city living-what can it do for us? Significance. 2012;9(4):4-7.

5. Batistič S, Van Der Laken P. History, evolution and future of big data and analytics: a bibliometric analysis of its relationship to performance in organizations. Br J Manag. 2019;30(2):229-51.

6. Bharadwaj AS. (2000). A resource-based perspective on information technology capability and firm performance: an empirical investigation, MIS quarterly, 169-196.

7. Beckhard R. Organizational issues in the team delivery of comprehensive health care. Milbank Mem Fund. 1972;50:287-316.

8. BenMark G, Klapdor S, Kullmann M, Sundararajan R. (2017). How retailers can drive profitable growth through dynamic pricing. McKinsey \& Company. Recuperado de https://www. mckinsey. 
com/industries/retail/our-insights/howretailers-can-drive-profitable-growth-throughdynamic-pricing.

9. Bernard M. (2018). American Express: How Big Data And Machine Learninghttps://www.bernardmarr.com/default.asp?contentID=1263.

10. Braun V, Clarke V. Using thematic analysis in psychology. Qualitative research in psychology. 2006;3(2):77-101.

11. Brown B, Chul M, Manyika J. Are you ready for the era of 'big data. McKinsey Q. 2011;4:24-7p30.

12. Chae $\mathrm{HC}$, Koh $\mathrm{CH}$, Prybutok VR. Information technology capability and firm performance: contradictory findings and their possible causes. MIS quarterly. 2014;38:305-26.

13. Chen DQ, Preston DS, Swink M. How the use of big data analytics affects value creation in supply chain management. Journal of Management Information Systems. 2015;32(4):4-39.

14. Cummings TG, Worley CG. (2009). Organization Development and Change. Eighth edition. Thompson South-Western, Mason, $\mathrm{OH}$.

15. De Mauro A, Greco M, Grimaldi M, Ritala P. (2018). In (Big) Data we trust: Value creation in knowledge organizations-Introduction to the special issue.

16. Du G, Zhang X, Ni S. (2018, October). Discussion on the application of big data in rail transit organization. In International Conference on Smart Vehicular Technology, Transportation, Communication and Applications (pp. 312-318). Springer, Cham.

17. Ekambaram A, Sørensen A, Bull-Berg H, Olsson NO. The role of big data and knowledge management in improving projects and project-based organizations. Procedia computer science. 2018;138:851-8.

18. Fouladirad M, Neal J, Ituarte JV, Alexander J, Ghareeb A. (2018). Entertaining Data: Business Analytics and Netflix. International Journal of Data Analysis And Information Systems. 10(1).

19. Galbraith JR. Organizational design challenges resulting from big data. Journal of Organization Design. 2014;3(1):2-13.

20. George JP, Chandra KS. (2020, May). Asset Productivity in Organisations at the Intersection of Big Data Analytics and Supply Chain Management. In International Conference on Image Processing and Capsule Networks (pp. 319-330). Springer, Cham.

21. Glanz K, Rimer BK, Viswanath K, editors. Health behavior and health education: theory, research, and practice. John Wiley \& Sons; 2008.

22. Gobble MM. Outsourcing innovation. Research-Technology Management. 2013;56(4):64-7.

23. Grant RM. Contemporary strategy analysis: Text and cases edition. Wiley; 2010. p. 776.

24. Günther WA, Mehrizi MHR, Huysman M, Feldberg F. Debating big data: A literature review on realizing value from big data. J Strateg Inf Syst. 2017;26(3):191-209.

25. Gupta M, George JF. Toward the development of a big data analytics capability. Inf Manag. 2016;53(8):1049-64.gu.

26. Hadida AL, Lampel J, Walls WD, Joshi A. (2020). Hollywood studio filmmaking in the age of Netflix: a tale of two institutional logics. Journal of Cultural Economics, 1-26. 
27. Hao S, Zhang H, Song M. Big Data, Big Data Analytics Capability, and Sustainable Innovation Performance. Sustainability. 2019;11:7145. https://doi.org/10.3390/su11247145.

28. Harinen T, Li B. Using Causal Inference to Improve the Uber User Experience. Uber Engineering; 2019. 29. Haryadi AF, Hulstijn J, Wahyudi A, Van Der Voort H, Janssen M. (2016, December). Antecedents of big data quality: An empirical examination in financial service organizations. In 2016 IEEE International Conference on Big Data (Big Data) (pp. 116-121). IEEE.

30. HBS (2020). Next Big Sound - moneyball for music? - Digital Innovation < https://digital.hbs.edu/platform-digit/submission/next-big-sound-moneyball-for-music/>

31. Hewage TN, Halgamuge MN, Syed A, Ekici G. Big Data Techniques of Google, Amazon, Facebook and Twitter. Journal of Communications. 2018;13(2):94-100.

32. Higgins JP, Green S, Scholten RJPM. (2008). Maintaining reviews: updates, amendments and feedback. Cochrane handbook for systematic reviews of interventions, 31.

33. Jha AK, Agi MA, Ngai EW. A note on big data analytics capability development in supply chain. Decis Support Syst. 2020;138:113382.

34. Jokonya O. (2015, November). Towards a conceptual framework for big data adoption in organizations. In 2015 International Conference on Cloud Computing and Big Data (CCBD) (pp. 153160). IEEE.

35. Judger N. (2016). The thematic analysis of interview data: An approach used to examine the influence of the market on curricular provision in Mongolian higher education institutions. Hillary place papers, 3rd edition, University of Leeds.

36. Khine P, Shun W. Big Data for Organizations: A Review. Journal of Computer Communications. 2017;5:40-8.

37. Kim MK, Park JH. Identifying and prioritizing critical factors for promoting the implementation and usage of big data in healthcare. Information Development. 2017;33(3):257-69.

38. Kolajo T, Daramola O, Adebiyi A. Big data stream analysis: a systematic literature review. Journal of Big Data. 2019;6(1):1-30.

39. Kwon O, Lee N, Shin B. Data quality management, data usage experience and acquisition intention of big data analytics. Int J Inf Manage. 2014;34(3):387-94.

40. Li B, Harinen T. (2019). Mediation Modeling at Uber: Understanding Why Product Changes Work (and Don't Work). Uber Engineering.

41. Liberati A, Altman DG, Tetzlaff J, Mulrow C, Gøtzsche PC, loannidis JP, ... Moher D. The PRISMA statement for reporting systematic reviews and meta-analyses of studies that evaluate health care interventions: explanation and elaboration. J Clin Epidemiol. 2009;62(10):e1-34.

42. Manyika J, Chui M, Brown B, Bughin J, Dobbs R, Roxburgh C, Byers H, A. Big data: The next frontier for innovation, competition, and productivity. McKinsey Global Institute; 2011.

43. Madhlangobe W, Wang L. (2018, June). Assessment of Factors Influencing Intent-to-Use Big Data Analytics in an Organization: Pilot Study. In 2018 IEEE 20th International Conference on High 
Performance Computing and Communications; IEEE 16th International Conference on Smart City; IEEE 4th International Conference on Data Science and Systems (HPCC/SmartCity/DSS) (pp. 17101715). IEEE.

44. Marashi PS, Hamidi H. (2018). Business Challenges of Big Data Application in Health Organization. In Competitiveness in emerging markets, Springer, Cham, 569-584. doi:10.1007/978-3-319-717227_28.

45. McAfee A, Brynjolfsson E, Davenport TH, Patil DJ, Barton D. Big data: the management revolution. Harvard business review. 2012;90(10):60-8.

46. Mikalef P, Pappas IO, Krogstie J, Giannakos M. Big data analytics capabilities: a systematic literature review and research agenda. IseB. 2018;16(3):547-78.

47. Mikalef P, Boura M, Lekakos G, Krogstie J. Big data analytics and firm performance: Findings from a mixed-method approach. J Bus Res. 2019;98:261-76.

48. Mikalef P, Krogstie J, Pappas IO, Pavlou P. Exploring the relationship between big data analytics capability and competitive performance: The mediating roles of dynamic and operational capabilities. Inf Manag. 2020;57(2):103169.

49. Miller S. Collaborative approaches needed to close the big data skills gap. Journal of Organization Design. 2014;3(1):26-30.

50. Mneney J, Van Belle JP. (2016, January). Big data capabilities and readiness of South African retail organisations. In 2016 6th International Conference-Cloud System and Big Data Engineering (Confluence) (pp. 279-286). IEEE.

51. Nguyen T, Li ZHOU, Spiegler V, leromonachou P, Lin Y. Big data analytics in supply chain management: A state-of-the-art literature review. Comput Oper Res. 2018;98:254-64.

52. Page MJ, McKenzie JE, Bossuyt PM, Boutron I, Hoffmann TC, Mulrow CD, ... Moher D. (2021). The PRISMA 2020 statement: an updated guideline for reporting systematic reviews. BMJ, 372.

53. Pei L. (2020). Application of Big Data Technology in Construction Organization and Management of Engineering Projects. Journal of Physics: Conference Series, 1616, 012002. doi:10.1088/17426596/1616/1/012002.

54. Popovič A, Hackney R, Tassabehji R, Castelli M. (2016). The impact of big data analytics on firms' high value business performance. Information Systems Frontiers, 1-14.

55. Posavec AB, Krajnović S. May). Challenges in adopting big data strategies and plans in organizations. In: 2016 39th International Convention on Information and Communication Technology, Electronics and Microelectronics (MIPRO). IEEE; 2016. pp. 1229-34.

56. Prestby J, Wandersman A. An Empirical Exploration of a Framework of Organizational Viability: Maintaining Block Organizations. The Journal of Applied Behavioral Science. 1985;21(3):287-305.

57. Rialti R, Marzi G, Silic M, Ciappei C. (2018). Ambidextrous organization and agility in big data era: the role of business process management systems. Business Process Management Journal. 
58. Rialti R, Marzi G, Ciappei C, Busso D. (2019). Big data and dynamic capabilities: a bibliometric analysis and systematic literature review. Management Decision.

59. Richard B. (2017). Hotel chains: survival strategies for a dynamic future. Journal of Tourism Futures..

60. Russom P. Big data analytics. TDWI best practices report fourth quarter. 2011;19(4):1-34.

61. Saetang W, Tangwannawit S, Jensuttiwetchakul T. The effect of technology-organizationenvironment on adoption decision of big data technology in Thailand. International Journal of Electrical Computer Engineering (IJECE). 2020;10(6):6412. doi:10.11591/ijece.v10i6.pp6412-6422.

62. Santhanam R, Hartono E. (2003). Issues in linking information technology capability to firm performance. MIS quarterly, 125-153.

63. Schein EH. Organizational Culture and Leadership. San Francisco: Jossey-Bass; 1985.

64. Schneider B, Ehrhart MG, Macey WH. Organizational climate and culture. Ann Rev Psychol. 2013;64:361-88.

65. Selçuk AA. A guide for systematic reviews: PRISMA. Turkish Archives of Otorhinolaryngology. 2019;57(1):57.

66. Shuradze G, Wagner HT. (2016, January). Towards a conceptualization of data analytics capabilities. In 2016 49th Hawaii International Conference on System Sciences (HICSS) (pp. 5052-5064). IEEE.

67. Sousa MJ, Pesqueira AM, Lemos C, Sousa M, Rocha Á. Decision-making based on big data analytics for people management in healthcare organizations. Journal of medical systems. 2019;43(9):1-10.

68. Tiwari S, Wee HM, Daryanto Y. Big data analytics in supply chain management between 2010 and 2016: Insights to industries. Comput Ind Eng. 2018;115:319-30.

69. Wahyudi A, Farhani A, Janssen M. (2018, October). Relating big data and data quality in financial service organizations. In Conference on e-Business, e-Services and e-Society (pp. 504-519). Springer, Cham.

70. Wamba SF, Gunasekaran A, Akter S, Ren SJF, Dubey R, Childe SJ. Big data analytics and firm performance: Effects of dynamic capabilities. J Bus Res. 2017;70:356-65.

71. Wamba SF, Mishra D. (2017). Big data integration with business processes: a literature review. Business Process Management Journal.

72. Wang Y, Hajli N. Exploring the path to big data analytics success in healthcare. J Bus Res. 2017;70:287-99.

73. Wang Y, Kung L, Gupta S, Ozdemir S. Leveraging big data analytics to improve quality of care in healthcare organizations: A configurational perspective. Br J Manag. 2019;30(2):362-88.

74. Wu YK, Chu NF. Introduction of the transtheoretical model and organisational development theory in weight management: A narrative review. Obesity research clinical practice. 2015;9(3):203-13.

75. Zan KK. (2019, January). Prospects For Using Big Data To Improve The Effectiveness Of An Education Organization. In 2019 IEEE Conference of Russian Young Researchers in Electrical and Electronic Engineering (EICOnRus) (pp. 1777-1779). IEEE. 
76. Zhang Y, Huang T, Bompard EF. Big data analytics in smart grids: a review. Energy Informatics. 2018;1(1):8.

\section{Figures}

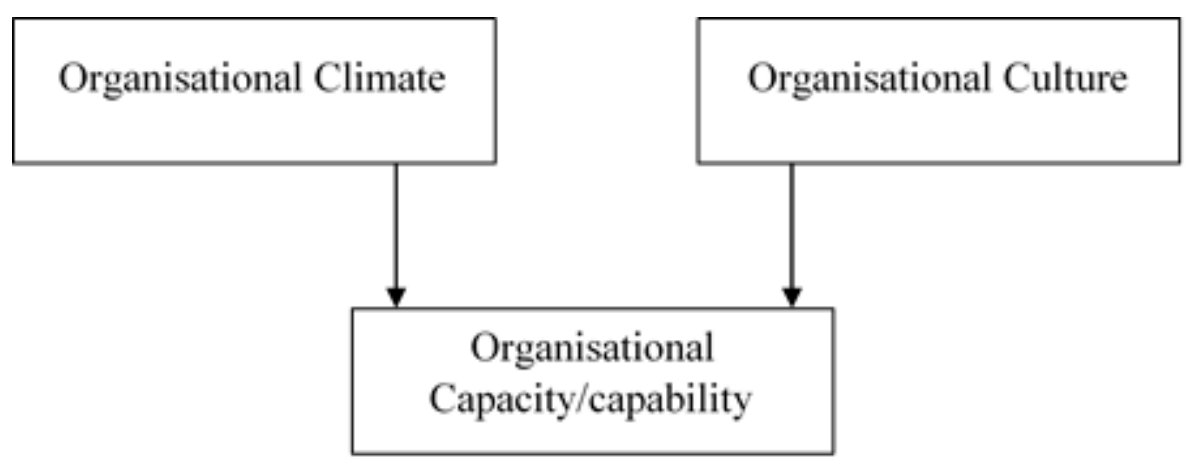

\section{Figure 1}

Framework of modified organisational development theory (Glanz et al., 2008) 
Records found: $\mathbf{2 3 0 5 8 7}$

Database list:

Science direct $-\mathbf{1 5 5 5 1 8}$

Web of Science - $\mathbf{8 8 3 4}$

IEEE - 3235

Springer Link - 63000
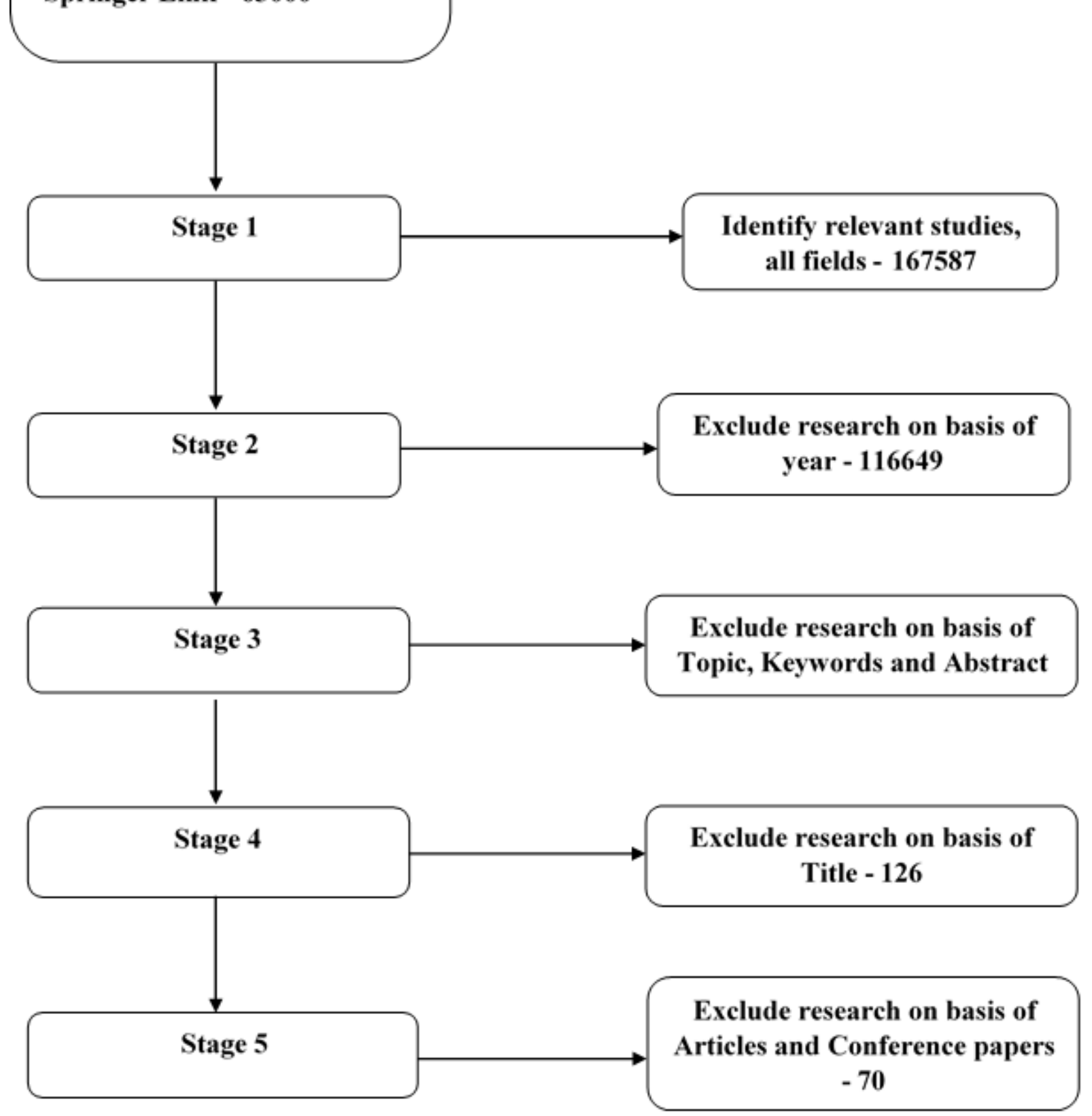

Figure 2

Stages of the selection processes 


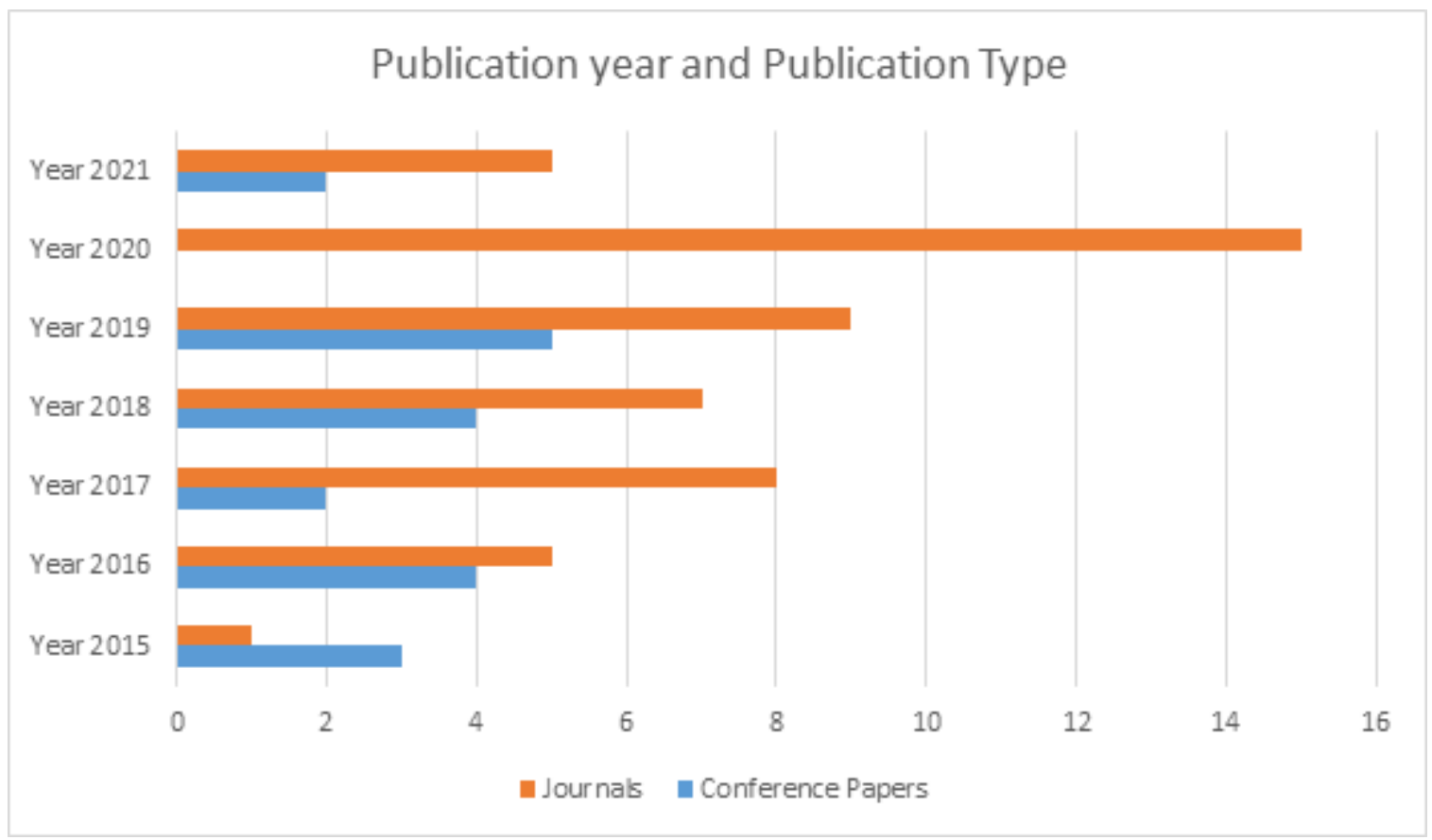

Figure 3

Distribution of publications by year and publication type Research Articles

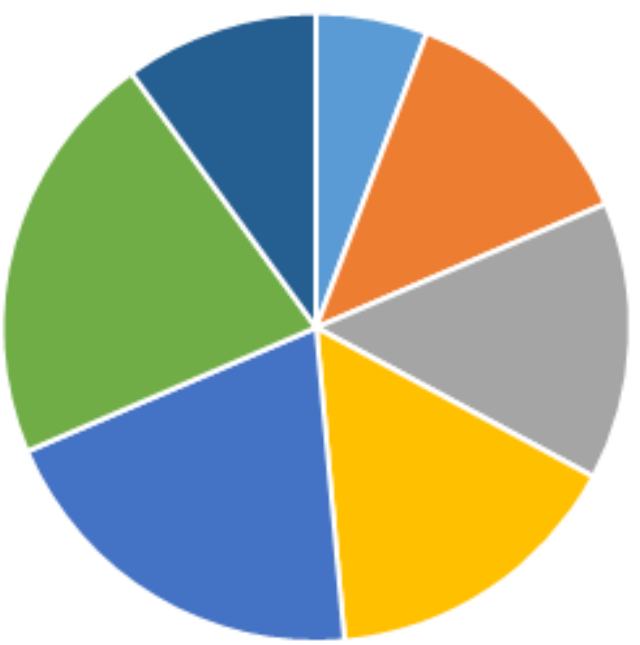

| 2015 | $2016 \quad$ | $2017 \quad$ || $2018 \quad 2019 \quad$ | 2020

Figure 4

Chart of publication year for numbers of articles 


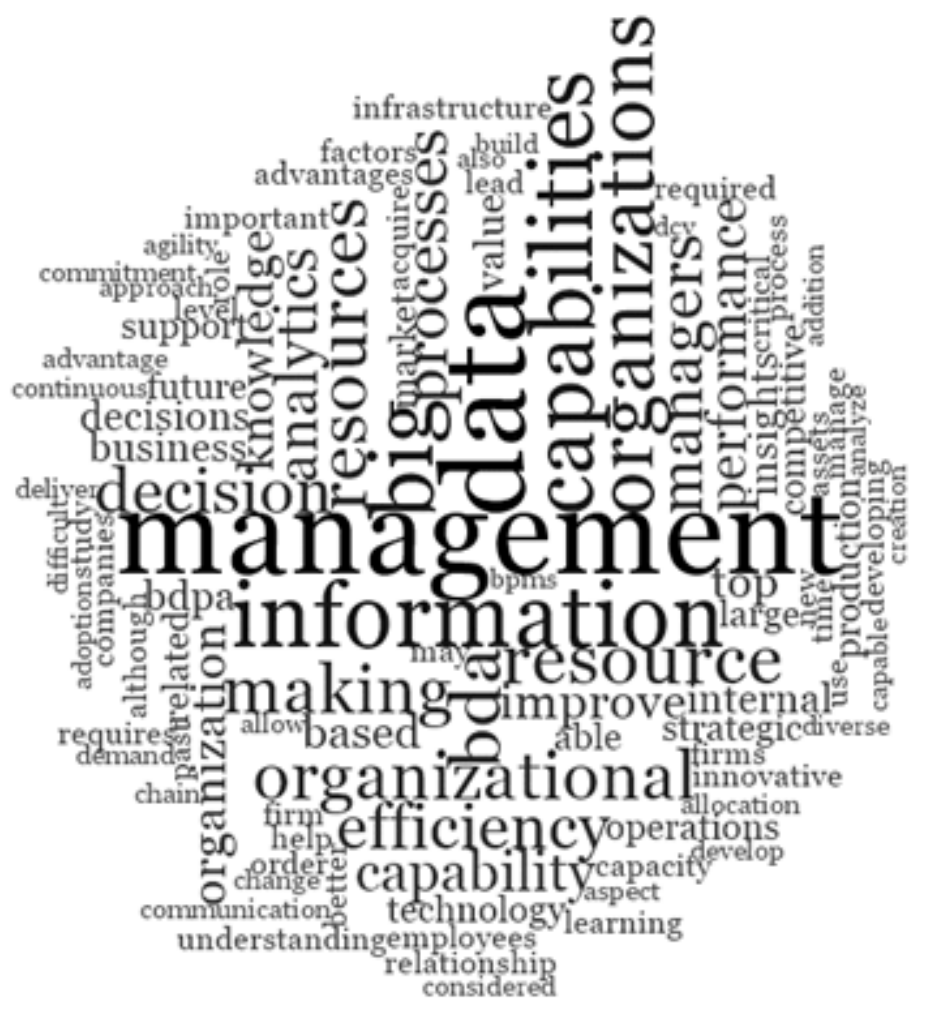

Figure 5

Thematic Analysis using Nvivo 12

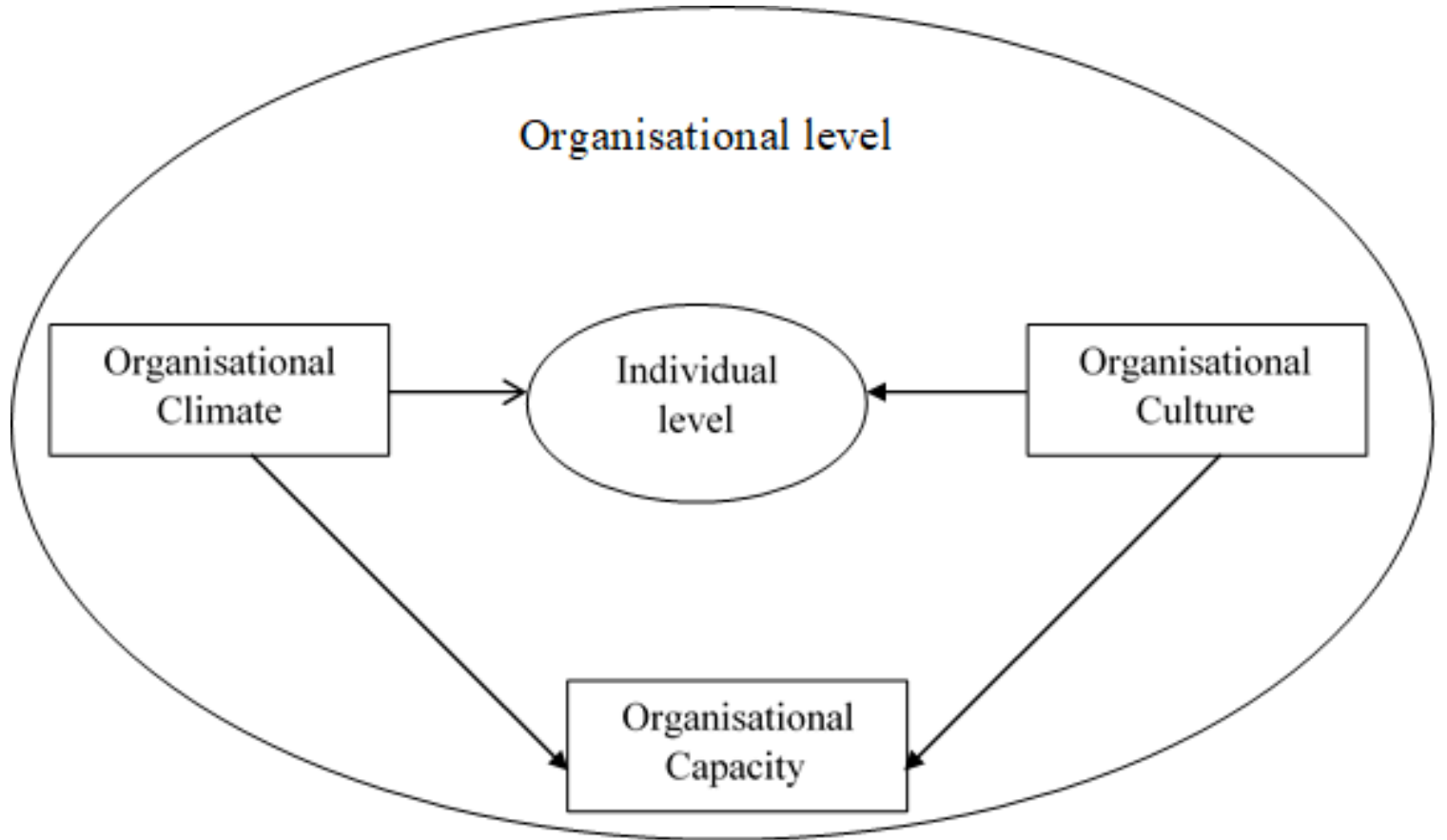

Figure 6

The framework of organisational development theory (Wu \& Chu, 2014) 


\section{Big Data Analytics Capability}

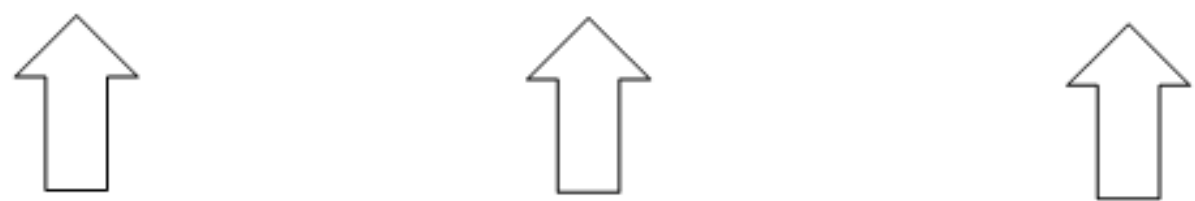

\begin{tabular}{|c|c|c|}
\hline Tangible & Human & Intangible \\
\hline $\begin{array}{l}\text { - Technology } \\
\text { - Basic resources }\end{array}$ & - Technical Skills & $\begin{array}{l}\text { Intensity of } \\
\text { Organisational } \\
\text { Learning }\end{array}$ \\
\hline
\end{tabular}

Figure 7

Classification of Big Data Resources (adapted from Gupta \& George, 2016)

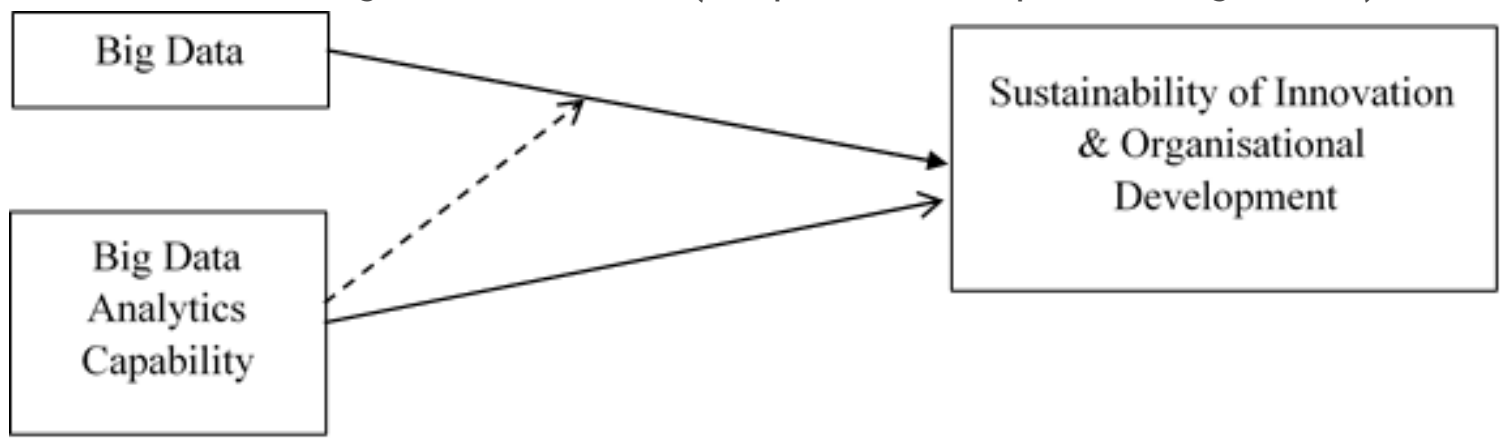

Figure 8

Theoretical framework (adapted from Hao, Zhang \& Song, 2019) 


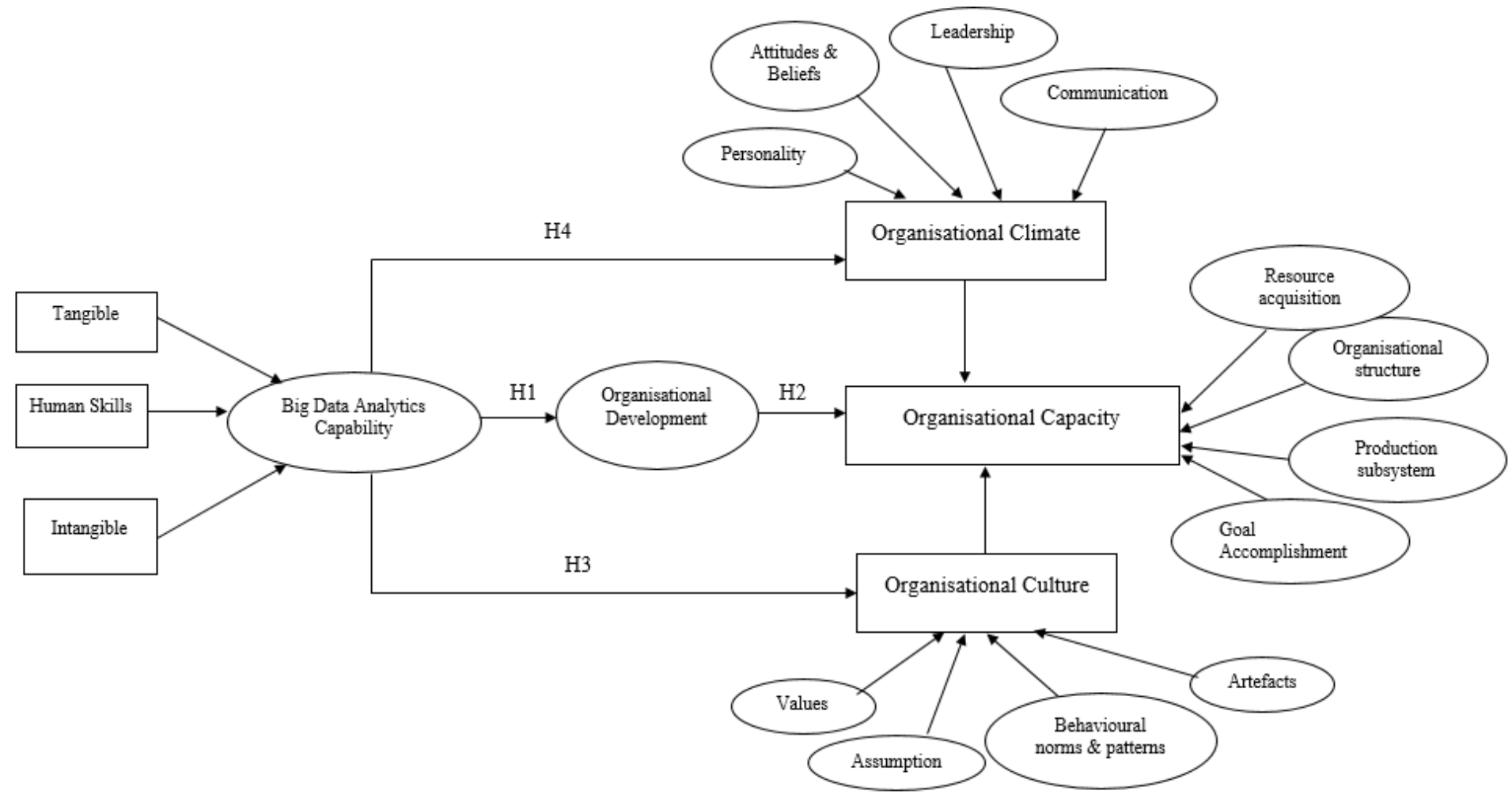

Figure 9

Proposed interpretation in the research model

\section{Supplementary Files}

This is a list of supplementary files associated with this preprint. Click to download.

- AppendixASamplesdetailstable.docx 